\title{
Efeitos de um Análogo de Reforçamento Negativo sobre a Seleção de Culturantes*
}

\author{
Damom Cruz Ribeiro ${ }^{1, * *}\left(\mathbb{D}\right.$, Thais Maria Monteiro Guimarães ${ }^{1,2} \mathbb{\bullet}$, Carlos Rafael Fernandes \\ Picanço $^{1}$ (D), Marcus Bentes de Carvalho Neto ${ }^{1}$ (D, \& Emmanuel Z. Tourinho ${ }^{1}$ \\ ${ }^{1}$ Universidade Federal do Pará, Belém, PA, Brasil \\ ${ }^{2}$ Beehave: Soluções Comportamentais, Vale do São Francisco, BA-PE, Brasil
}

\begin{abstract}
RESUMO - O presente estudo investigou os efeitos de um análogo de reforçamento negativo sobre a seleção de culturantes e, diferentemente de estudos anteriores, buscou eliminar a interferência da punição negativa de outros culturantes. Três microculturas de laboratório, com três participantes cada, foram expostas a um delineamento ABAB. Os participantes escolhiam entre linhas coloridas e numeradas de 1 a 10. Na condição de Reforçamento Positivo (A), os culturantes-alvo produziam consequências culturais. Na condição de Reforçamento Negativo (B), as consequências culturais eram subtraídas a cada 30 s, mas os culturantes-alvo podiam adiar a perda dessas consequências. $O$ análogo de reforçamento negativo, assim como o de reforçamento positivo, selecionou os culturantes-alvo sem a interferência de contingências punitivas acidentais.
\end{abstract}

PALAVRAS-CHAVES: seleção cultural, metacontingência, reforçamento negativo, controle aversivo

\section{Effects of an Analogue of Negative Reinforcement on the Selection of Culturants}

\begin{abstract}
The present research investigated the effect of a negative reinforcement analog on the selection of culturants and, unlike previous studies, sought to eliminate the interference of the negative punishment of other culturants. Three laboratory microcultures, with three participants in each of them, were exposed to an ABAB design. The participants chose between colored lines, numbered from 1 to 10. In the Positive Reinforcement condition (A), target culturants produced cultural consequences. In the Negative Reinforcement condition (B), cultural consequences were subtracted every 30 seconds, but target culturants could delay the loss of those consequences. The analog of negative reinforcement, as well as that of positive reinforcement, selected target culturants without the interference of accidental punitive contingencies.
\end{abstract}

KEYWORDS: cultural selection, metacontingency, negative reinforcement, aversive control

São notáveis os esforços de Skinner (1953/2003) para abordar fenômenos culturais com as ferramentas conceituais da Análise do Comportamento, aí incluído o modo causal de seleção por consequências, com base no qual Skinner (1981) aponta as práticas culturais como produto de um terceiro nível de seleção, em adição à filogênese e ontogênese. Glenn $(1986,2004)$ parte dessa interpretação e define o que constitui uma unidade de análise no nível de seleção cultural, referida com o conceito de metacontingência.

Uma metacontingência descreve a relação funcional entre culturantes (comportamentos entrelaçados de vários indivíduos e seus produtos) e consequências culturais (eventos ambientais selecionadores) (Glenn, 1986, 1988, 2003; Glenn et al., 2016). Glenn (1988) descreveu contingências comportamentais entrelaçadas como contingências nas quais o comportamento de um indivíduo e/ou suas consequências têm função de eventos ambientais para o comportamento de outro indivíduo. Hunter (2012) propôs o termo culturante para descrever uma unidade integrada de contingências comportamentais entrelaçadas que resultam em um produto agregado. Desse modo, compreende-se a metacontingência enquanto uma unidade de análise do terceiro nível de seleção, que remete a uma relação probabilística entre a recorrência de um culturante e sua consequência cultural.

\footnotetext{
* Apoio: CAPES.

** E-mail: damom@outlook.com

- Submetido: 17/06/2019; Revisado: 08/06/2020; Aceito: 16/06/2020
} 
Diversos estudos têm investigado fenômenos sociais, tomando por base o conceito de metacontingência. Uma parcela dessas pesquisas tem focado processos análogos à seleção no nível operante, como esquemas de reforçamento (Soares et al., 2019; Soares et al., 2015), discriminação operante (Vieira, 2010), autocontrole ético (Borba et al., 2017) e controle aversivo (Alves et al., 2018; Guimarães et al, 2019a; Saconatto \& Andery, 2013).

O pequeno número de investigações experimentais sobre controle aversivo em metacontingências não acompanha a relevância deste tema para a compreensão de questões de grande importância social. Essa forma de controle é apontada por Skinner (1953/2003; 1986) e Sidman (1989/2003) como predominante em muitas culturas, sendo frequentemente utilizada em nossos sistemas organizacionais, desde nosso ordenamento jurídico até nossas relações interpessoais cotidianas.

Dentre os poucos estudos que investigaram operações de controle aversivo em metacontingências, o de Saconatto e Andery (2013) teve por objetivo avaliar o efeito do reforçamento negativo na seleção de metacontingências e sua replicação em diferentes gerações de uma microcultura de laboratório. Cada participante deveria inserir um número de 0 a 9 em espaços vazios apresentados na tela de um computador. O programa apresentava números acima desses espaços e, caso a soma dos números fornecidos pelo programa e pelo participante resultasse em um número ímpar, o participante produzia reforçadores positivos para si em forma de pontos trocáveis por dinheiro (operante). Contudo, os participantes deveriam produzir resultados em ordem crescente para evitar a perda de bônus (culturante) não produzido pelos participantes, ou seja, o resultado da soma do segundo participante deveria ser maior que o do primeiro e menor que o do terceiro, configurando-se, assim, uma metacontingência análoga ao processo de reforçamento negativo que ocorre com operantes. Os autores sugerem que houve seleção dos comportamentos operantes e do culturantealvo; no entanto, salientam que a seleção por análogos de reforçamento negativo ocorreu apenas na sexta geração, o que consideraram como uma seleção tardia, comparativamente com os resultados de estudos similares com análogos de reforçamento positivo (Brocal, 2010; Caldas, 2009).

O estudo de Alves et al. (2018) objetivou verificar os efeitos de um procedimento análogo a reforçamento negativo sobre a recorrência de culturantes em microculturas de laboratório com um delineamento de reversão $A B A B$ e BABA. Os participantes tinham acesso a uma figura com 10 linhas coloridas e numeradas e a tarefa era escolher uma das linhas por ciclo, sendo que a escolha de linhas ímpares produzia consequências individuais reforçadoras positivas durante as condições A e B. No início do experimento, os participantes recebiam 200 fichas que eram trocadas, no final do experimento, por itens escolares a serem doados a uma escola pública. Enquanto na condição A não havia consequência cultural programada, na condição B, escolhas dos participantes que não atendessem ao critério do culturante-alvo resultavam na perda de uma ficha por ciclo. O critério definido para o culturante-alvo consistia na escolha de linhas com cores diferentes. Desse modo, os participantes poderiam se comportar no sentido de evitar a perda da ficha, mas não para produzi-las. Os resultados demonstram a seleção dos comportamentos operantes pelas consequências individuais. Além disso, a recorrência do culturante-alvo nas duas microculturas analisadas foi atribuída à aplicação de um procedimento análogo ao reforçamento negativo, um resultado que corrobora aqueles obtidos por Saconatto e Andery (2013).

Nos arranjos experimentais utilizados por Alves et al. (2018) e Saconatto e Andery (2013), as consequências aversivas eram apresentadas ao final de cada ciclo, de modo que todos os culturantes possíveis, exceto os culturantesalvo da metacontingência de reforçamento negativo, produziam punidores negativos (i.e., perda de fichas e bônus, respectivamente), o que pode ter relação com a redução da recorrência desses culturantes. Uma vez que havia diversos culturantes sujeitos à punição negativa, mas apenas um culturante sujeito ao reforçamento negativo, os culturantes-alvo do análogo de reforçamento negativo não eram os únicos eventos para os quais havia consequências culturais programadas. Desse modo, não é possível atribuir com precisão a seleção dos culturantes-alvo à manipulação de estímulos reforçadores negativos, dado o efeito colateral de estímulos punidores negativos.

Outro ponto importante a ser destacado é que para que a perda de um estímulo seja aversiva é necessário que esse estímulo seja um reforçador positivo. No entanto, nos experimentos de Alves et al. (2018) e Saconatto e Andery (2013), o valor reforçador das consequências reforçadoras (i.e., ficha e bônus) removidas na fase de reforçamento negativo não foi diretamente avaliado, apenas presumido.

Dado o alcance dos estudos iniciais sobre os efeitos do reforçamento negativo na seleção de culturantes (Alves et al., 2018; Saconatto \& Andery, 2013), e diante dos problemas encontrados nesses estudos, o presente trabalho incluiu estratégias metodológicas que poderiam permitir uma avaliação mais precisa do papel de um análogo de reforçamento negativo (fuga e esquiva) na seleção de culturantes em microculturas de laboratório. Para tentar isolar o efeito do reforçamento negativo daquele da punição negativa sobre o culturante-alvo, uma estimulação aversiva era apresentada no início do análogo de reforçamento negativo e sua suspensão (fuga) ou adiamento (esquiva) era contingente à ocorrência do culturante-alvo, não sendo possível que essa estimulação aversiva ocorresse inadvertidamente como consequência de outros possíveis culturantes. Com relação à avaliação das propriedades reforçadoras positivas dos estímulos removidos no análogo de reforçamento negativo, esses estímulos foram apresentados, inicialmente, como consequência de um culturante-alvo em um análogo de reforçamento positivo. Desse modo, o aumento na ocorrência desse culturante seria suficiente para revelar a função reforçadora positiva dos estímulos. 


\section{MÉTODO}

\section{Participantes}

O experimento teve a participação de nove estudantes universitários com idade média de 20 anos, provenientes de diversos cursos, exceto Psicologia e Economia. Os participantes compuseram três microculturas, com três participantes cada uma. As microculturas 1 e 3 foram formadas por três participantes do sexo masculino cada, e a microcultura 2, por três participantes do sexo feminino. Os participantes foram recrutados pelo pesquisador responsável e por assistentes de pesquisa nos corredores da universidade. Os agendamentos das sessões experimentais e alocação dos participantes em cada microcultura foram feitos considerando apenas a disponibilidade dos participantes (o que indica o não balanceamento das microculturas quanto ao gênero). Cada participante assinou um Termo de Consentimento Livre e Esclarecido para participar do experimento.

Esta pesquisa foi aprovada pelo Comitê de Ética de Pesquisa com Humanos (Parecer № 3.141.680), em atendimento à Resolução $\mathrm{N}^{\circ} 466$, de 12 de dezembro de 2012, do Conselho Nacional de Saúde (CNS).

\section{Ambiente e Equipamentos}

A pesquisa foi conduzida nas dependências de um laboratório que desenvolve pesquisas sobre seleção cultural. Duas salas foram utilizadas, uma sala de espera para os participantes aguardarem o início da pesquisa e uma sala onde ocorreu a coleta de dados, esta última com dois ambientes (de controle e de coleta de dados) separados por um vidro de observação unilateral.

$\mathrm{Na}$ sala de coleta de dados, uma câmera registrou todo o experimento. Três cadeiras foram dispostas para os participantes, uma ao lado da outra e em frente a uma mesa, sobre a qual havia três notebooks com o software Free-Mtrix para o registro das respostas dos participantes. Sobre uma bancada, havia uma TV LCD e ao lado dela foram exibidos itens escolares e um painel com fotos de doações de itens escolares de pesquisas anteriores do laboratório. A disposição dos objetos na sala pode ser vista na Figura 1. No outro ambiente da sala, os pesquisadores controlaram o software e estiveram à disposição para qualquer eventualidade.

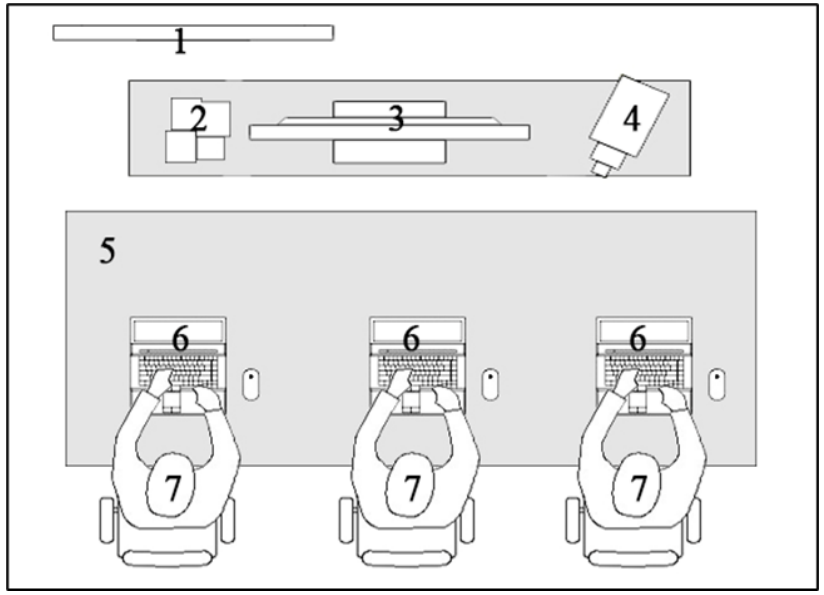

Figura 1. Sala Experimental:

Nota. (1) painel, (2) itens escolares, (3) TV LCD, (4) filmadora, (5) mesa, (6) notebooks, (7) participantes.

A coleta dos dados foi realizada com o auxílio de uma versão modificada do software Free-mtrix (disponível em https://github.com/lacs-ufpa/free-mtrix/tree/damom), desenvolvida especificamente para experimentos sobre seleção cultural. A interface deste software exibe uma figura constituída de 10 linhas numeradas de 1 a 10 , nas cores amarela, verde, vermelha, azul e roxa, de modo que cada cor ocorre em uma linha par e em uma linha ímpar. A interface do software exibida nos notebooks pode ser vista no painel superior da Figura 2. Em uma TV LCD, visível a todos, eram apresentados os contadores das consequências individuais e culturais produzidas e um temporizador que aparecia em determinado momento da tarefa experimental (descrito a seguir). A interface do software exibida na TV LCD a todos os participantes pode ser vista no painel inferior da Figura 2.

\section{Procedimento}

As três microculturas foram expostas a um delineamento ABAB (ver Tabela 1). Durante as condições A, estava em operação uma metacontingência análoga a reforçamento positivo, por isso essas condições serão referidas como Reforçamento Positivo. Nas condições B, estava em vigor uma metacontingência análoga a reforçamento negativo, assim essas condições serão nomeadas de Reforçamento

Tabela 1

Delineamento Experimental $A B A B$

\begin{tabular}{|c|c|c|c|c|}
\hline \multirow{2}{*}{ Condição } & \multicolumn{2}{|c|}{ Contingência } & \multicolumn{2}{|c|}{ Metacontingência } \\
\hline & Resposta & Consequência & Culturante & Consequência cultural \\
\hline A: Reforçamento positivo & & & $\begin{array}{c}\text { Culturante 1: } \\
\text { Azul+Vermelho+Outra cor }\end{array}$ & Produzir 1 item escolar \\
\hline B: Reforçamento negativo & Escolher números ímpares & Produzir 1 ficha individual & $\begin{array}{c}\text { Culturante 2: } \\
\text { Verde+Amarelo+Outra cor }\end{array}$ & $\begin{array}{l}\text { Adiar perda de itens } \\
\text { escolares }\end{array}$ \\
\hline
\end{tabular}




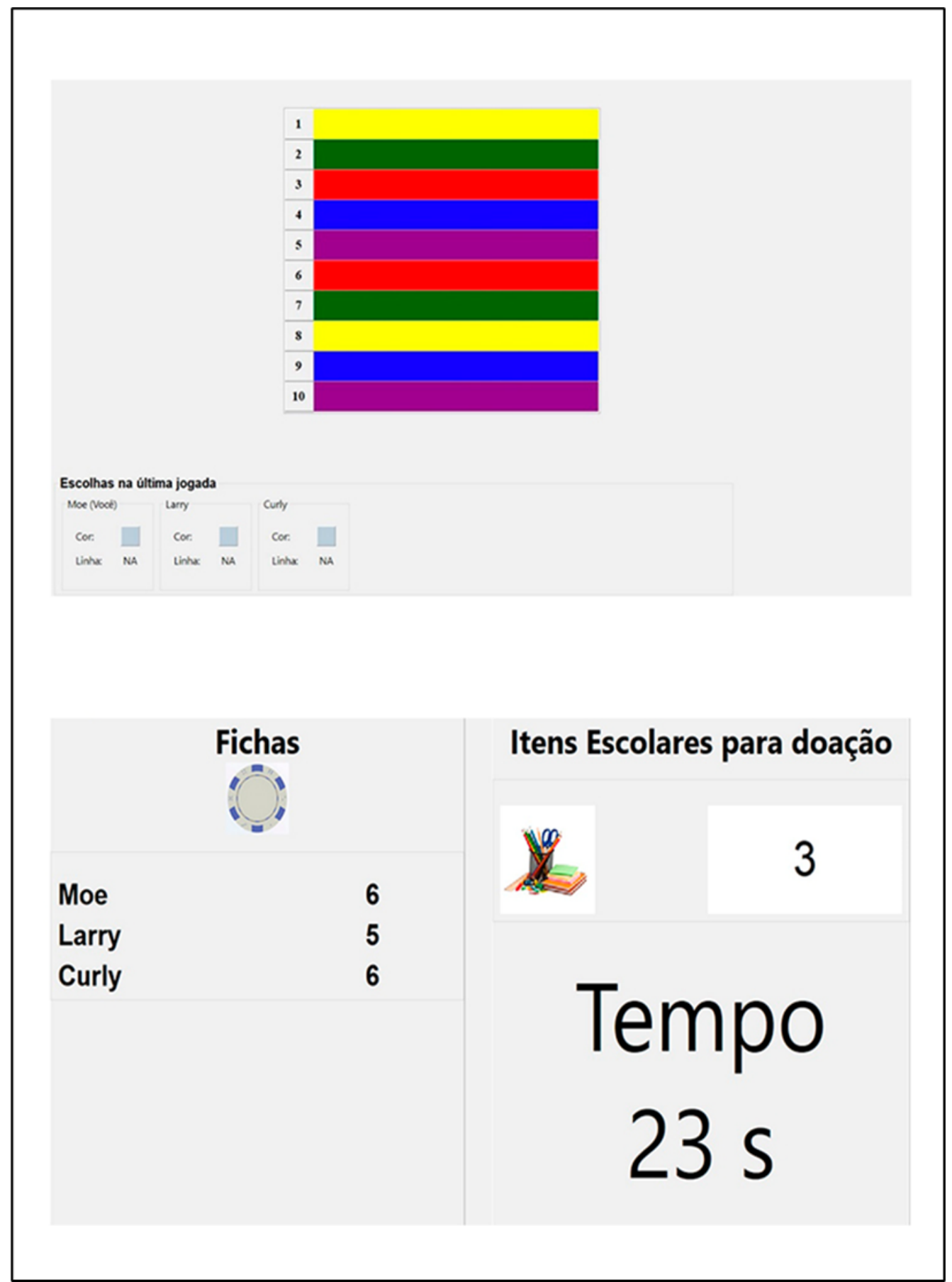

Figura 2. Interface do Software Free-Mtrix

Nota. exibida nos notebooks de cada participante (painel superior) e exibida na TVC LCD visível para todos os participantes (painel inferior). Ver o texto para mais detalhes.

Negativo. Tanto nas condições de Reforçamento Positivo, quanto naquelas de Reforçamento Negativo, além da metacontingência havia uma contingência operante em vigor.

\section{Tarefa e contingências de reforçamento}

Antes do início das sessões experimentais, foi dada a cada participante uma cópia da instrução abaixo e, em seguida, essa instrução foi lida em voz alta pelo pesquisador.
Você participará de uma tarefa na qual deverá escolher uma das linhas numeradas de 1 a 10, nas cores amarelo, verde, vermelho, azul e roxo, na ocasião em que o software indicar. Cada escolha pode lhe render uma ficha no valor de $R \$ 0,03$. A soma das fichas será contabilizada no contador sinalizado com seu nome na tela e, ao final da tarefa, será trocado pelo valor correspondente. Vocês poderão produzir itens escolares (lápis, borrachas, canetas, apontadores etc.) que serão doados a uma creche municipal de Belém, e poderão indicar uma creche ao fim do estudo. Os itens escolares serão registrados de forma 
cumulativa no contador à direita na sua tela, à medida em que se acumulam itens. Vocês poderão perder itens escolares. Quando isso ocorrer, um item será subtraído do contador que mostra a quantidade de itens acumulados. Vocês poderão interagir livremente. Caso precisem fazer anotações, podem utilizar estas canetas e folhas. O computador avisará o fim da tarefa. Após o experimento, será marcada uma data para a entrega dos itens escolares. Caso queiram, vocês poderão participar desse momento.

Após a leitura da instrução, o software indicava que os participantes deveriam escolher e clicar em uma das linhas dispostas na figura, sendo o participante 1 o primeiro a escolher, seguido dos participantes 2 e 3 . Dada essa sequência, um ciclo estava completo. As respostas dos participantes eram computadas pelo software e exibidas no notebook de cada participante. As consequências individuais tinham seus valores somados e atualizados para os participantes a cada resposta, e as consequências culturais, a cada ciclo. Ambas eram apresentadas na TV LCD a cada ciclo completado.

A consequência operante (individual) era contingente à escolha de uma linha ímpar e consistia em uma ficha equivalente a $R \$ 0,03$. As fichas ganhas ao longo das condições experimentais foram trocadas pelo valor correspondente em dinheiro ao final do experimento.

Duas metacontingências foram programadas, uma em cada tipo de condição experimental. Na condição de Reforçamento Positivo, a ocorrência do culturante 1 (escolha de linhas das cores azul, vermelho e qualquer outra cor pelos três participantes) produzia a consequência cultural (adição de um item escolar ao contador, o qual mostrava a quantidade de itens acumulados até o momento) acompanhada de um som.

A mudança para a condição de Reforçamento Negativo era sinalizada pela mensagem "A partir de agora, os itens escolares poderão ser subtraídos" e pela mudança do contador de itens escolares acumulados, da cor preta para a cor laranja. Os itens escolares eram subtraídos a cada 30s, a partir do início dessa condição, e não havia um marcador da passagem de tempo disponível para os participantes. A subtração de um item era acompanhada pela mensagem "um item escolar foi subtraído". Nessa condição, a ocorrência do culturante 2 (escolha das cores verde e amarelo, combinadas com uma outra cor, pelos três participantes) produzia: (1) uma pausa de 30s na subtração dos itens escolares, que era sinalizada pela frase "subtração de itens escolares cessada por 30 segundos" acompanhada de um som; (2) uma mudança da cor do contador de itens da cor laranja para preto; e (3) o surgimento de um temporizador na TV LCD, em contagem regressiva. A cada recorrência do culturante 2 , essa última mensagem aparecia novamente, um som era emitido e o temporizador voltava a marcar $30 \mathrm{~s}$. Ao término da contagem dos $30 \mathrm{~s}$ sem a ocorrência do culturante programado, o temporizador desaparecia da TV LCD, o contador de itens escolares voltava a ser mostrado na cor laranja e os itens voltavam a ser subtraídos a cada 30s.

As metacontingências programadas não incluíam um requisito de ordem específica das cores escolhidas para a produção das consequências culturais; no entanto, era exigido que fossem três cores distintas. Assim, a "outra cor" se referiria a qualquer uma das três outras cores disponíveis na figura. Por exemplo, se durante a metacontingência análoga a reforçamento positivo, o Participante 1 escolhesse azul e o Participante 2 escolhesse vermelho, o Participante 3 deveria escolher verde, amarelo ou roxo para que a consequência cultural fosse produzida. Uma vez que, durante todo o experimento, a escolha de linhas ímpares produzia consequências individuais, não havia concorrência entre a produção de consequências individuais e culturais. Destaca-se que, para qualquer outra combinação de três linhas além dos culturantes 1 e 2, não havia produção de consequência cultural.

No final do experimento, os itens escolares foram doados a uma instituição de ensino infantil.

O encerramento da condição de Reforçamento Positivo ocorria ao serem finalizados 100 ciclos. O critério para o encerramento da condição de Reforçamento Negativo foi a perda de todos os itens escolares produzidos pelo culturante 1 na condição de Reforçamento Positivo ou após 100 ciclos. Nesse sentido, as condições análogas a reforçamento negativo só teriam 100 ciclos caso ocorresse a seleção cultural pela metacontingência programada.

\section{Análise dos dados}

Foram analisadas as ocorrências da escolha de linhas ímpares pelos participantes das microculturas, bem como a ocorrência dos culturantes, tanto aqueles mantidos por reforçamento negativo quanto aqueles mantidos por reforçamento positivo, a cada bloco de 10 ciclos, no decorrer de todas as condições experimentais.

\section{RESULTADOS}

\section{Microcultura I}

O painel superior da Figura 3 apresenta a porcentagem de ocorrência de culturantes reforçados positivamente (culturante 1) e negativamente (culturante 2), em blocos de
10 ciclos, para a Microcultura 1. O experimento teve 400 ciclos completos e duração de 1 h e 33 min.

Na condição de Reforçamento Positivo, a ocorrência do culturante 1 variou nos primeiros ciclos, mas passou a ocorrer em $100 \%$ dos ciclos do bloco 6 até o bloco 10 , 


\section{MICROCULTURA 1}

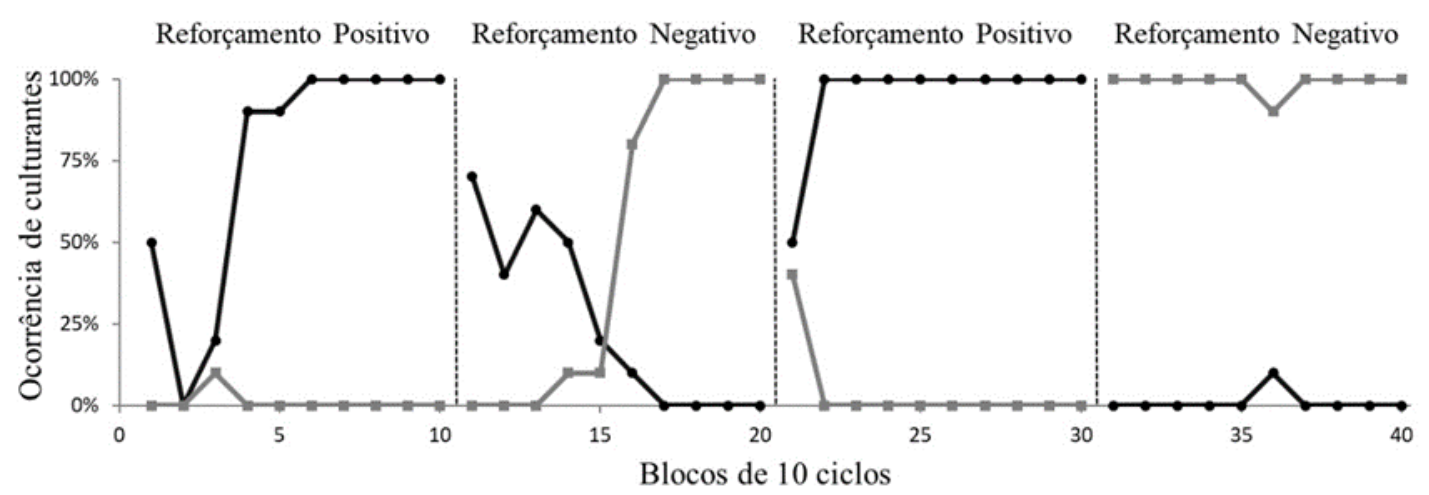

- Culturante 1 Culturante 2

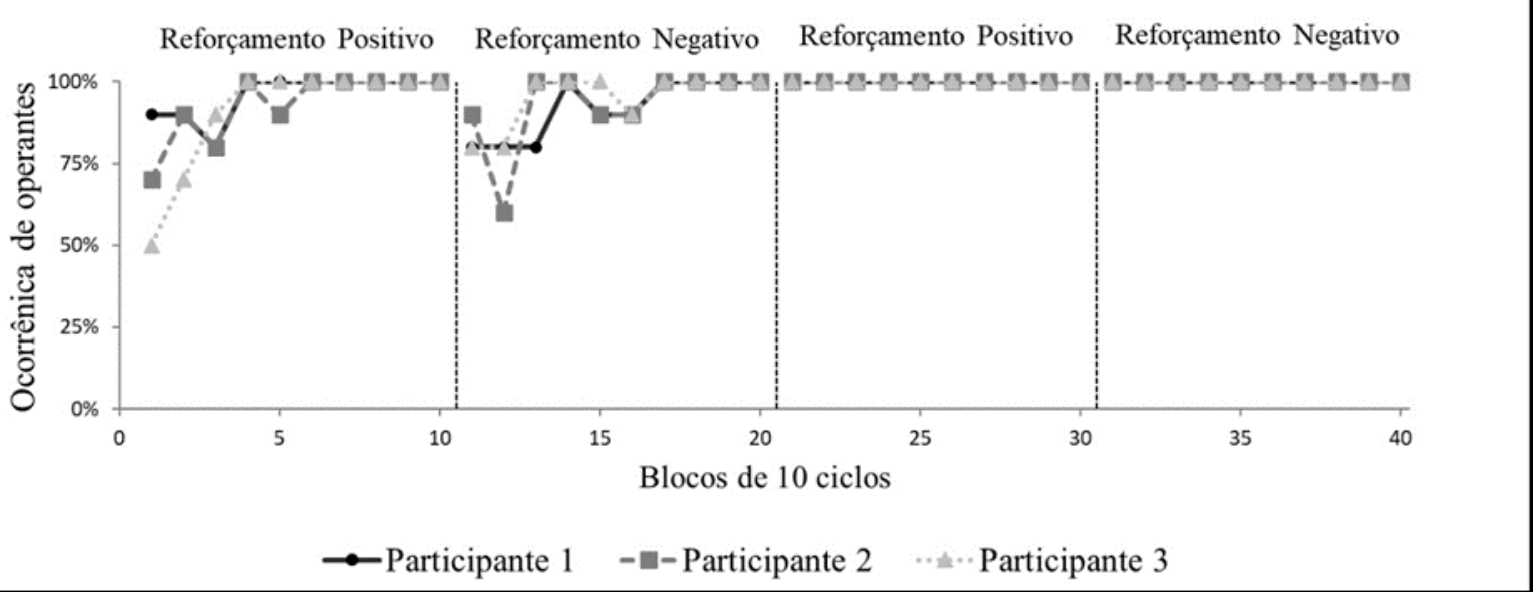

Figura 3. Porcentagem de Ocorrência de Culturantes Microcultura 1

Nota. Culturantes reforçados positivamente e culturantes reforçados negativamente (painel superior), e operantes reforçados positivamente (painel inferior), em blocos de 10 ciclos, para a Microcultura 1.

enquanto o culturante 2, para o qual não havia consequência programada, ocorreu apenas uma vez no bloco 3 . Na condição de Reforçamento Negativo, a ocorrência do culturante 1 decresceu até o bloco 17 , no qual atingiu $0 \%$ e permaneceu assim até o final da condição. O culturante 2 não foi emitido até o bloco 13 , quando passou progressivamente a ocorrer e atingir $100 \%$ no bloco 17 , e assim permanecer até o bloco 20. Uma segunda condição de Reforçamento Positivo foi iniciada a partir do bloco 21 . Nesta condição, a ocorrência do culturante 1 atingiu $100 \%$ no bloco 22 , enquanto nesse mesmo bloco o culturante 2 atingiu $0 \%$. A partir daí, não houve alterações para ambos os culturantes até o encerramento da condição. No ciclo 31 , foi iniciada a segunda condição de Reforçamento Negativo, durante a qual a ocorrência do culturante 1 atingiu $0 \%$ e a do culturante 2 atingiu $100 \%$ no bloco 31 , permanecendo assim até o final da condição (exceto por uma única ocorrência do culturante 1 durante o bloco 36 ).
O painel inferior da Figura 3 apresenta a porcentagem de ocorrência de operantes reforçados positivamente pela escolha de linhas ímpares a cada bloco de 10 ciclos para a Microcultura 1. Nos primeiros ciclos da condição de Reforçamento Positivo, houve um aumento na ocorrência dos operantes. No entanto, na condição Reforçamento Negativo, houve uma queda inicial na produção de consequências individuais, seguida por uma rápida recuperação. Após terem atingido $100 \%$ de ocorrência no bloco 17 , os três participantes permaneceram fazendo escolhas em linhas ímpares até o final do experimento.

\section{Microcultura 2}

O painel superior da Figura 4 apresenta a porcentagem de ocorrência do culturante 1 , reforçado positivamente, e do culturante 2, reforçado negativamente, em blocos de 10 


\section{MICROCULTURA 2}

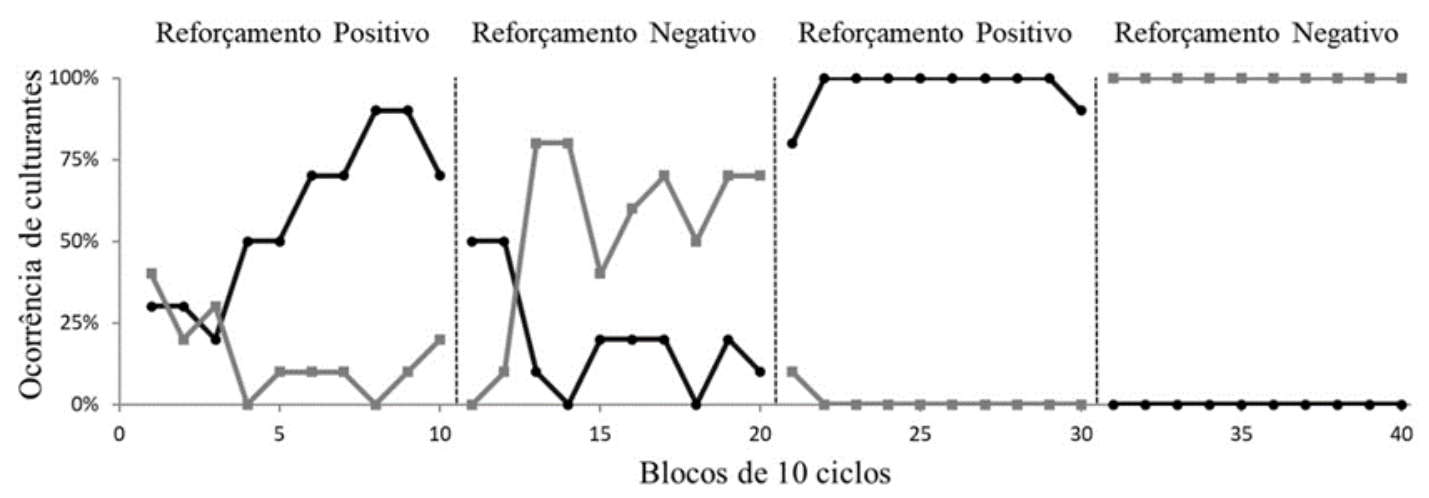

- Culturante 1

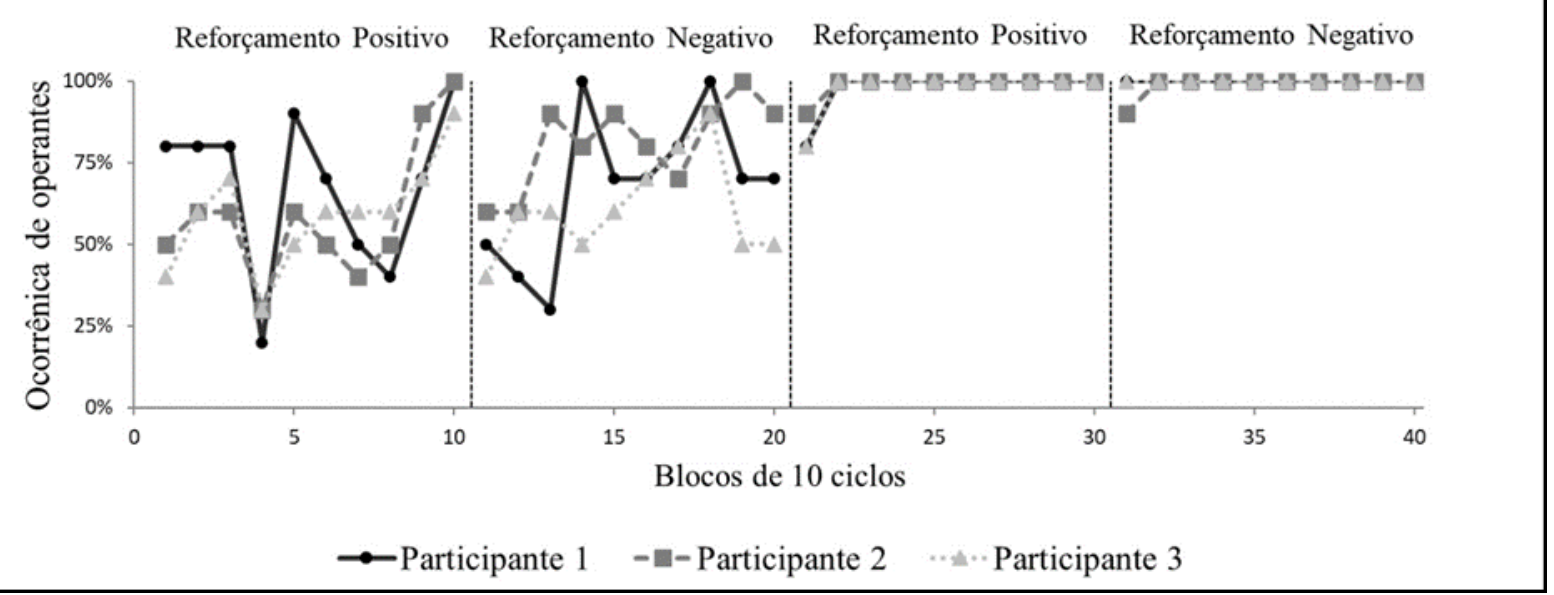

Figura 4. Porcentagem de Ocorrência de Culturantes Microcultura 2

Nota. Culturantes reforçados positivamente e culturantes reforçados negativamente (painel superior), e operantes reforçados positivamente (painel inferior), em blocos de 10 ciclos, para a Microcultura 2.

ciclos para a Microcultura 2. O experimento foi concluído com 400 ciclos completos e teve duração de $1 \mathrm{~h}$ e $54 \mathrm{~min}$.

Durante a condição de Reforçamento Positivo, a ocorrência do culturante 1 , para o qual havia consequência cultural programada, variou nos ciclos iniciais e passou a aumentar a partir do bloco 4 , chegando a atingir $90 \%$ nos blocos 8 e 9 . O culturante 2 foi mais frequente no bloco 1 $(40 \%)$, e nos demais, sua ocorrência se situou entre $0 \%$ e $20 \%$. Na condição de Reforçamento Negativo, a ocorrência do culturante 1 foi reduzida com a retirada da consequência cultural, no entanto, mesmo após ter atingido $0 \%$ no bloco 14 , voltou a aumentar, mas não ultrapassou $20 \%$. O culturante 2 não ocorreu no bloco 11, mas apresentou aumento considerável no bloco 13, passando a ocorrer entre $40 \%$ e $80 \%$ até o fim da condição. No retorno à condição de Reforçamento Positivo, após contato com a consequência cultural programada, a ocorrência do culturante 1 atingiu
$80 \%$ no bloco 21 e se manteve em $100 \%$ nos blocos 22 a 29. Com a retirada da consequência cultural, o culturante 2 apresentou uma redução imediata, deixando de ocorrer a partir do bloco 22. Durante toda a segunda condição de Reforçamento Negativo, a ocorrência do culturante 1 foi $0 \%$, enquanto a do culturante 2 foi $100 \%$.

O painel inferior da Figura 4 apresenta a porcentagem de ocorrência de operantes reforçados positivamente pela escolha de linhas ímpares, a cada bloco de 10 ciclos, para a Microcultura 2. A escolha de linhas ímpares pelos participantes apresentou instabilidade durante a primeira e segunda condições, apesar de ocorrerem acima de 50\% na maioria dos blocos para os três participantes. Apenas após o bloco 22, na terceira condição experimental, o operante passou a ocorrer em $100 \%$ dos ciclos até o fim da sessão experimental, exceto por uma escolha de linha par feita pelo participante 3 durante o bloco 31 . 


\section{Microcultura 3}

O painel superior da Figura 5 apresenta a porcentagem de ocorrência dos culturantes 1 e 2 , reforçados positiva e negativamente, respectivamente, em blocos de 10 ciclos, para a Microcultura 3. O experimento foi concluído com 400 ciclos completos e teve duração de $2 \mathrm{~h}$ e $22 \mathrm{~min}$.

Na condição Reforçamento Positivo, a ocorrência do culturante 1 aumentou a partir do bloco 5 e atingiu $100 \%$ nos últimos dois blocos. O culturante 2 , apesar de apresentar ocorrências de $20 \%$ em alguns blocos, deixou de ocorrer nos dois blocos finais da condição. Durante a condição de Reforçamento Negativo, a ocorrência do culturante 1 diminuiu nos primeiros dois blocos, situando-se entre 0 e $20 \%$ nos blocos seguintes. A ocorrência do culturante 2 correspondeu a $60 \%$ logo no primeiro bloco desta condição e, em seguida, variou entre 30 e $80 \%$ até o fim da condição. Ao retornar à condição de Reforçamento Positivo, o culturante 1 registrou ocorrência de $90 \%$ já no primeiro bloco e permaneceu com ocorrência entre 70 e $100 \%$ até o final desta condição. O culturante 2 , por sua vez, teve apenas quatro ocorrências. Durante a segunda condição de Reforçamento Negativo, o culturante 1 ocorreu apenas durante os blocos 31 e 34 . A ocorrência do culturante 2 oscilou nos blocos iniciais, mas a partir do bloco 36 se estabilizou em $100 \%$ até o fim da condição.

O painel inferior da Figura 5 apresenta a porcentagem de ocorrência de operantes reforçados positivamente pela escolha de linhas ímpares, a cada bloco de 10 ciclos, para a Microcultura 3. As escolhas de linhas ímpares se tornaram predominantes na segunda metade da condição de Reforçamento Positivo, mas na primeira condição de Reforçamento Negativo, a ocorrência dessas escolhas diminuiu, variando entre 20 e $80 \%$. Durante as demais condições do experimento, houve redução dessa variação de modo que a escolha de linhas ímpares passou a predominar.

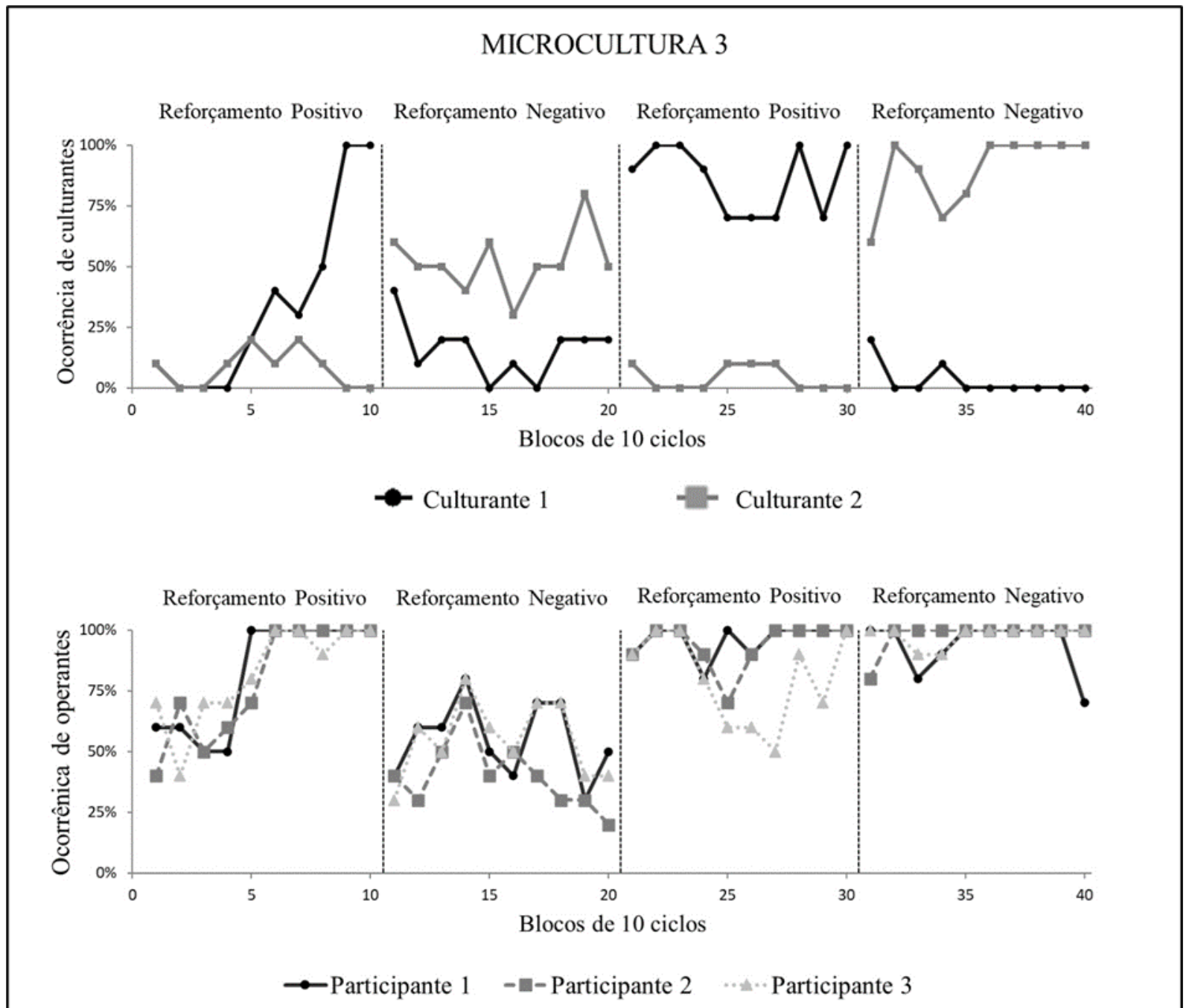

Figura 5. Porcentagem de Ocorrência de Culturantes Microcultura 3

Nota. Culturantes reforçados positivamente e culturantes reforçados negativamente (painel superior), e operantes reforçados positivamente (painel inferior), em blocos de 10 ciclos, para a Microcultura 3. 


\section{DISCUSSÃO}

Nas três microculturas analisadas, a programação de análogos de reforçamento positivo e de reforçamento negativo produziram aumentos na ocorrência dos culturantesalvos, corroborando os resultados relatados por Guimarães et al. (2019b) e Vichi et al. (2009) ao usarem um análogo de reforçamento positivo, e por Alves et al. (2018) e Saconatto e Andery (2013) ao usarem um análogo de reforçamento negativo. Diferentemente desses dois últimos estudos, no entanto, o efeito do reforçamento negativo ocorreu sem a interferência de contingências acidentais (i.e., punição negativa de outros culturantes) e o valor reforçador dos estímulos removidos nas condições de reforçamento negativo foram diretamente avaliados. Assim como nos estudos acima mencionados, também foram verificados aumentos na ocorrência de operantes em função das consequências reforçadoras individuais.

Todas as microculturas tiveram as condições de reforçamento negativo finalizadas pelo critério de número de ciclos, ou seja, 100 ciclos foram cumpridos, uma vez que não houve a perda de todos os itens escolares produzidos pelo culturante 1 em nenhuma das condições de reforçamento negativo. Mais do que isso, a manutenção dos itens escolares produzidos pela recorrência do culturante 2 durante a condição de reforçamento negativo aponta para a efetividade da consequência cultural programada em selecionar a coordenação dos comportamentos dos participantes para a evitação da perda dos itens escolares.

Com a programação utilizada neste estudo, a seleção dos culturantes pela metacontingência análoga a reforçamento negativo guarda semelhanças com o processo referido na esquiva de Sidman. No procedimento clássico apresentado por Sidman (1953), um choque elétrico era programado em intervalos regulares; no entanto, a emissão de uma resposta adiava a apresentação do próximo choque por um período fixo de tempo. No presente estudo, a perda de itens escolares era programada a cada $30 \mathrm{~s}$, mas se o culturante 2 ocorresse, essa perda era suspensa por 30s. No estudo de Sidman, respostas operantes foram selecionadas e mantidas por adiarem a apresentação do estímulo aversivo; similarmente, no estudo aqui relatado, culturantes também foram selecionados e mantidos quando produziam o adiamento de um evento cultural aversivo. Essa similaridade fortalece a afirmação de que os culturantes-alvo foram selecionados por reforçamento negativo.

Na primeira condição de Reforçamento Negativo da microcultura 1, a ocorrência do culturante 1 apresentou uma queda gradual até chegar a $0 \%$. A partir daí, o culturante 2 passou a ocorrer em $100 \%$ dos ciclos. Nas microculturas 2 e 3, houve maior variação na ocorrência dos dois culturantes programados. Embora o culturante 2 tenha predominado na primeira condição de Reforçamento Negativo, o culturante 1 continuou a ocorrer, mesmo que com uma baixa frequência. Uma vez que nesta condição houve a retirada da consequência cultural que mantinha o culturante 1 na condição de Reforçamento Positivo anterior, a recorrência deste culturante pode ser entendida como um efeito análogo ao da extinção operante. A extinção operante é uma propriedade do reforço, de modo que com a suspensão do estímulo reforçador, a frequência da resposta retorna aos níveis observados antes de seu reforçamento (Catania, 1998/1999). Em todas as microculturas, esse efeito foi observado para o culturante 1 após a suspensão da consequência cultural; também foi observada uma certa variabilidade na sua ocorrência, o que também é um efeito comum da extinção operante. Portanto, os participantes dessas microculturas apresentaram aumento da variabilidade na ocorrência dos culturantes enquanto coordenavam suas respostas, na tentativa de produzir itens escolares durante a condição de Reforçamento Negativo. Desse modo, as pausas de 30s na subtração de itens escolares que eram produzidas pelo culturante 2 foram utilizadas pela microcultura para reproduzir a combinação de cores que produziu itens escolares na condição de Reforçamento Positivo, talvez para fazer novas combinações e, assim, voltar a produzir itens escolares, pois outras combinações foram produzidas além do culturante 1. Outros estudos sobre seleção cultural já demonstraram efeito similar. Por exemplo, Baia et al. (2017) utilizou um procedimento análogo à extinção operante, no qual demonstrou aumento na variabilidade dos entrelaçamentos nas microculturas. $\mathrm{O}$ mesmo fenômeno pode ser observado na segunda condição de Reforçamento Negativo da microcultura 3, quando, apesar do aumento da ocorrência do culturante 2 , algumas ocorrências do culturante 1 foram observadas antes que o culturante 2 passasse a ocorrer sem nenhuma outra tentativa de produzir itens escolares.

A introdução da metacontingência análoga ao reforçamento negativo também afetou os comportamentos dos participantes das microculturas no nível operante. Uma vez que essa metacontingência entrou em vigor e houve uma maior variabilidade na emissão de culturantes, os participantes chegaram a fazer menos escolhas por linhas ímpares quando houve mudança da primeira para a segunda condição. Tal variação ocorreu para as três microculturas durante a primeira exposição à condição de Reforçamento Negativo, mas não na segunda exposição a essa condição, o que sugere um aumento na sensibilidade às contingências programadas no decorrer do experimento.

Em conclusão, este estudo avaliou o efeito de um análogo de reforçamento negativo sobre a seleção de culturantes em microculturas. Devido ao arranjo experimental utilizado, ficou demonstrado o controle efetivo por metacontingências de reforçamento negativo e garantidas as propriedades reforçadoras das consequências culturais removidas durante 
as condições de reforçamento negativo. Os resultados obtidos corroboram estudos com objetivo similar (Alves et al., 2018; Saconatto \& Andery, 2013) e permitem demonstrar que o comportamento de membros de uma microcultura é sensível às consequências programadas tanto no nível operante quanto cultural. Esses resultados sugerem, no geral, que a seleção cultural e a seleção operante ocorreram sem prejuízo para ambas, confirmando a independência entre esses dois níveis de seleção (Tourinho, 2013). Tal achado também foi demonstrado em estudos com outras contingências, tais como punição (Guimarães et al., 2019a) e suspensão da consequência cultural (i.e., extinção) (Baia et al. 2017).

Estudos futuros com o presente arranjo experimental poderão avaliar os efeitos das metacontingências programadas com substituição de participantes, ou seja, com mudança de gerações nas microculturas, para avaliação da transmissão cultural. Tal procedimento tem sido comum em estudos que avaliam fenômenos culturais com arranjos de metacontingência em análogos de reforçamento positivo
(Amorim, 2010; Borba et al., 2017; Brocal, 2010; Caldas, 2009; Guimarães et al., 2019a; Leite, 2009; Vichi, 2012).

Devido a um efeito de ordem de exposição às condições, a aquisição dos repertórios comportamentais necessários para realização da tarefa experimental ocorreu durante a exposição à metacontingência análoga ao reforçamento positivo. Incluir tarefas experimentais diferentes nas condições A e B permitiria avaliar a aquisição dos repertórios nas microculturas por meio de análogos de reforçamento negativo e comparar os resultados com aqueles de metacontingências programadas para reforçamento positivo. Outras possíveis alterações seriam a retirada das consequências individuais, uma vez que, utilizando o presente protocolo de pesquisa, programar a seleção de respostas operantes pode reduzir à metade o universo de combinações de três linhas que produzem consequência cultural. Modificações que permitam produzir e analisar o efeito de extinção em metacontingências análogas a reforçamento negativo também seriam relevantes.

\section{REFERÊNCIAS}

Alves, L. F. C., Carvalho Neto, M. B., \& Tourinho, E. Z. (2018). Efeitos de Consequências Culturais Análogas a Reforçamento Negativo sobre a Recorrência de Culturantes em Microculturas de Laboratório. Acta Comportamentalia, 26(2), 217-231.

Amorim, V. C. (2010). Análogos Experimentais de Metacontingências: Efeitos da Intermitência da Consequência Cultural (Dissertação de Mestrado não publicada). Pontifícia Universidade Católica de São Paulo, São Paulo, Brasil.

Araujo, V. M., Melo, C. M., \& Haydu, V. B. (2016). Código Penal Brasileiro como Descrição de Prática Cultural: Uma Análise Comportamental de Contingências e Metacontingências. Revista Brasileira de Análise do Comportamento, 11(2), 147156. http://doi.org/10.18542/rebac.v11i2.1943

Baia, F. H., Lemes, I. G., Biano, A. B. C., Pereira, R. S. C., \& de Sousa, L. D. (2017). Efeitos da Programação e Suspensão de Metacontingências sobre Operantes e Culturantes. Acta Comportamentalia, 25(4), 495-510.

Borba, A., Silva, B. R., Tourinho, E. Z. \& Glenn, S. S. (2017). Effects of Cultural Consequences on the Interlocking Behavioral Contingencies of Ethical Self-Control. The Psychological Record, 67(3), 399-411. https://doi.org/10.1007/s40732-0170231-6

Brocal, A. L. (2010). Análogos Experimentais de Metacontingência: O Efeito da Retirada da Consequência Individual (Dissertação de Mestrado não publicada). Pontifícia Universidade Católica de São Paulo, São Paulo, Brasil.

Caldas, R. A. (2009). Análogos Experimentais de Seleção e Extinção de Metacontingências (Dissertação de Mestrado não publicada). Pontifícia Universidade Católica de São Paulo, São Paulo, Brasil.

Catania, A. C. (1999). Aprendizagem: Comportamento, Linguagem e Cognição (4a Ed., D. G. Souza, Org. Trad.). Artmed.

Glenn, S. S. (1986). Metacontingencies in Walden Two. Behavior Analysis and Social Action, 5, 2-8. https://doi.org/10.1007/ BF03406059

Glenn, S. S. (1988). Contingencies and Metacontingencies: Toward a Synthesis of Behavior Analysis and Cultural Materialism. The Behavior Analyst, 11(2), 161-179. https://doi.org/10.1007/ BF03392470
Glenn, S. S. (2003). Operant Contingencies and the Origin of Cultures. Em K. Lattal \& P. Chase (Orgs.), Behavior Theory and Philosophy (pp. 223-242). Kluwer Academic / Plenum Publishers. https://doi.org/10.1007/978-1-4757-4590-0_12

Glenn, S. S. (2004). Individual Behavior, Culture, and Social Change. The Behavior Analyst, 27(2), 133-151. https://doi. org/10.1007/BF03393175

Glenn, S. S., Malott, M. E., Andery, M. A. P. A., Benvenuti, M., Houmanfar, R. A., Sandaker, I., Todorov, J. C., Tourinho, E. Z., \& Vasconcelos, L. A. (2016). Toward consistent terminology in a behaviorist approach to cultural analysis. Behavior and Social Issues, 25, 11-27. https://doi.org/10.5210/bsi. v25i0.6634

Guimarães, T. M. M., Leite, F. L., Carvalho Neto, M. B., Tourinho, E. Z., \& Tonneau, F. (2019a). The Effects of Punishment in Laboratory Microcultures. Behavior and Social Issues, 28(1), 160-173. https://doi.org/10.1007/s42822-019-00004-z

Guimarães, T. M. M., Picanço, C. R. F., \& Tourinho, E. Z. (2019b). Effects of Negative Punishment on Culturants in a Situation of Concurrence between Operant Contingencies and Metacontingencies. Perspectives on Behavior Science, 42(4), 733-750. https://doi.org/10.1007/s40614-019-00224-z

Hunter, C. S. (2012). Analyzing Behavioral and Cultural Selection Contingencies. Revista Latinoamericana de Psicología, 44(1), 43-54.

Leite, F. L. (2009). Efeitos de Instruções e História Experimental sobre a Transmissão de Práticas de Escolha em Microculturas de Laboratório (Dissertação de Mestrado não publicada). Universidade Federal do Pará, Pará, Brasil.

Saconatto, A. T., \& Andery, M. A. P. A. (2013). Seleção por Metacontingências: Um Análogo Experimental de Reforçamento Negativo. Interação em Psicologia, 17(1), 1-10. http://doi.org/10.5380/psi.v17i1.26779

Sidman, M. (1953). Avoidance Conditioning with Brief Shock and No Exteroceptive Warning Signal. Science, 118(3058), 157158. https://doi.org/10.1126/science.118.3058.157

Sidman, M. (2003). Coerção e Suas Implicações. Livro Pleno.

Skinner, B. F. (1981) Selection by Consequences. Science, 213(4507), 501-504. https://doi.org/10.1126/science.7244649 
Skinner, B. F. (1986). What is Wrong with Daily Life in the Western World. American Psychologist, 41(5), 568-574. https://doi. org/10.1037/0003-066X.41.5.568

Skinner, B. F. (2003). Ciência e Comportamento Humano (11 a ed.). Martins Fontes.

Soares, P. F. R., Martins, J. C. T., Guimarães, T. M. M., Leite, F. L., \& Tourinho, E. Z. (2019). Effects of Continuous and Intermittent Cultural Consequences on Culturants in Metacontingency Concurrent with Operant Contingency. Behavior and Social Issues, 28(1), 189-202. https://doi.org/10.1007/s42822-01900009-8

Soares, P. F. R., Martins, J. C. T., Leite, F. L., \& Tourinho, E. Z. (2015). Seleção de Contingências Comportamentais Entrelaçadas por Consequências Culturais Intermitentes. Revista Brasileira de Análise do Comportamento, 11(2), 117124. https://doi.org/10.18542/rebac.v11i2.3780
Tourinho, E. Z. (2013). Cultural Consequences and Interlocking Behavioral Contingencies: Selection at the Cultural Level. Behavior and Philosophy, 41, 60-69. https://doi.org/10.2307/ behaphil.41.60

Vichi. C. (2012). Efeitos da Apresentação Intermitente de Consequências Culturais sobre Contingências Comportamentais Entrelaçadas e seus Produtos Agregados (Tese de Doutorado não publicada). Universidade Federal do Pará, Pará, Brasil.

Vichi. C., Andery. M. A. P. A., \& Glenn, S. S. (2009 A Metacontingency Experiment: The Effects of Contingent Consequences on Patterns of Interlocking Contingencies of Reinforcement. Behavior and Social Issues, 18(1), 41-57. https://doi.org/10.5210/bsi.v18i1.2292

Vieira, M. C. (2010). Condições Antecedentes Participam de Metacontingências? (Dissertação de Mestrado não publicada). Pontifícia Universidade Católica de São Paulo, São Paulo, Brasil. 